\title{
A Validation of Science Teaching Efficacy Belief Instrument for Biology Teachers
}

\author{
Agu, Philomena \\ Department of Curriculum and Instruction \\ Fairish Hall, University of Houston, Texas \\ United States \\ Ramsey, John \\ Department of Curriculum and Instruction \\ Fairish Hall, University of Houston, Texas \\ United States
}

\begin{abstract}
The state of Texas assumes certification tests with low and high biology contents yield teachers with equal teaching efficacy if candidates did not obtain an undergraduate degree in a teaching subject. But, the sense of efficacy of the generalist-certified teachers who took the test with only 30 percent life science contents may be impacted. Studies have used personal efficacy and outcome expectancy subscales in Science Teaching Efficacy Belief Instrument (STEBI) to measure teacher effectiveness. Few scales exist specifically for subject teachers teaching science in high schools. Hence, STEBI was adapted. This study assessed the validity and reliability of modified STEBI using data from 562 in-service biology teachers in public high schools. Principal Component Analysis supported the validity of the instrument, Confirmatory Factor Analysis failed. The reliability was established with Cronbach's alpha. The subscales were reliable; alpha was .81 and .81. STEBI could be adapted to study teaching efficacy beliefs of biology teachers.
\end{abstract}

Keywords: Beliefs, Instrument, Biology teachers, Personal efficacy; Outcome expectancy, Certification, Public school, Science

Riggs and Enochs (1990) deviated from using a general teacher efficacy belief instrument in their studyof science teaching efficacy beliefs of elementary teachers because of the "dependency of the construct upon a specific teaching situation" (Riggs \& Enochs, 1990, p. 7). Then, Riggs and Enochs developed a Science Teaching Efficacy Belief Instrument (STEBI). The STEBI was validated with in-service elementary teachers. Elementary science is usually taught as general science, unlike high school science, which is often taught as separate subjects. Hence, there is a need and opportunity to adapt STEBI particularly for high school science subject teachers and examine its psychometric properties.

II. Theoretical Framework

This study stemmed from the work of Bandura $(1977 ; 1986)$. Bandura theorized that personal efficacy and outcome expectancy predict human behavior such as choice of activities, how much effort to put in, and coping abilities in stressful situations. Typically, "People tend to avoid tasks and situations they believe exceed their capabilities but undertake and perform assuredly activities they judge themselves capable of handling" (Bandura, 1986 p. 393). Bandura stated that personal efficacy and outcome expectancy are related, but the subconstructs are to be treated differently because individuals may believe that a course of action will produce a particular outcome but question their capabilities to execute the necessary activities to attain the result. Situational circumstances such as a type of subject matter and an audience influence the level and strength of personal efficacy and outcome expectancy (Bandura, 1977).

In education, a "personal teaching efficacy is a belief in one's ability to teach effectively while teaching outcome expectancy is the belief that effective teaching will have a positive effect on student learning" (Enochs, Smith, \& Huinker,2000, p. 195). Both personal efficacy and outcome expectancy are termed teacher efficacy beliefs, "the extent to which teachers believes they can affect student achievement positively" (Riggs \& Enochs, 1990, p. 5). One will expect generalist certified biology teachers and life science certified biology teachers to have the ability to advance students' learning gains. 
Teacher scores on the teacher efficacy belief instrument were used in various studies to measure differences in the teachers' use of effective instructional pedagogy (Ashton \& Webb, 1986; Cakiroglu, Capa-Aydin, \& Hoy, 2012; Czerniak, 1989; Czerniak \& Schriver, 1994; Enochs et al., 2000) and their ability to increase students' academic achievement (Angel \& Moseley, 2009; Ashton \& Webb, 1986; Czerniak \& Schriver, 1994; Hoy \& Woolfolk, 1990; Lumpe, Czerniak, Haney, \& Beltyukova, 2012). Due to the specific nature of the construct, Riggs and Enochs (1990) developed Science Teaching Efficacy Belief Instrument (STEBI) specific for studies involving teaching science in elementary grades. Over the years, empirical researchers have adapted STEBI in studies involving efficacy of subject teachers such as STEBI-CHEM (Rubeck, 1990). This research project adapted STEBI-CHEM, a version of STEBI used in middle grades.

\section{Background}

The Science Teaching Efficacy Belief Instrument, a 25-item Likert scale, developed by Riggs and Enochs (1990) involved beliefs of elementary teacher in teaching and learning science. The data for developing the instrument were collected from in-service elementary teachers. Through factor analysis, Riggs and Enochs obtained two subscales (factors), Personal Science Teaching Efficacy Beliefand Science Teaching Outcome Expectancy. The first factor was defined by 13 items and the second with 12 variables. Riggs and Enochs (1990) recommended that the Science Teaching Efficacy Belief Instrument be used as a tool for studies involving elementary teachers' efficacy beliefs. Consequently, scholars adapted the instrument in various studies involving elementary teachers. For example, Wenner (2001) altered the wording of STEBI to obtain mathematics information and used the modified scale to compare efficacy beliefs of in-service and pre-service elementary school teachers in math and science. Also, Enochs, Smith, and Huinker (2000) adapted STEBI to study mathematics teaching efficacy beliefs of elementary school teachers.

In middle grade, Rubeck (1990) modified STEBI by replacing the word 'science' with 'chemistry' and measured efficacy beliefs of middle school teachers in teaching chemistry. Rubeck (1990) named the instrument Science Teaching Efficacy Belief Instrument for Chemistry (STEBI-CHEM). Through factor analysis, Rubeck obtained two factors consistent with STEBI (Riggs \& Enochs, 1990). Rubeck named the first subscale Self-efficacy in Chemistry Teaching and the second factor, Outcome Expectancy in Chemistry Teaching. In the STEBI-CHEM, items $2,3,5,6,8,12,17,18,19,21,22,23$, and 24, described factor one and items 1, 4, 7, 9, 10, 11, 13, 14, 15, 16,20 , and 25, defined factor two.

The, STEBI-CHEM was chosen for this study because the original STEBI is more for measures involving efficacy beliefs in teaching general science while STEBI-CHEM is specific to a particular science subject matter. The modified STEBI-CHEM is named "High School-Science Teaching Efficacy Belief Instrument (HS-STEBI) to differentiate it from STEBI and STEBI-CHEM. Each science subject matter is added with a hyphen at the back of HS-STEBI to obtain the physics scale, biology scale or chemistry scale. The biology scale was named HS-STEBIbio (Appendix B), and the physics scale HS-STEBI-phys. The chemistry instrument was named HS-STEBI-chem. The biology scale only is reported in this study.

\section{Research Question}

Is the adapted High School-Science Teaching Efficacy Belief Instrument-biovalid and reliable measure of personal efficacy and outcome expectancy in teaching biology?

Methods

The High School-Science Teaching Efficacy Belief Instrument- biology was first developed by modifying STEBICHEM. Changes were made on STEBI-CHEM by replacing the word chemistry with biology and by changing or deleting some phrases to suit the study. For example, "When students' grades in the chemistry section of science improve it is often due to their teacher having found a more effective teaching approach" is an item in STEBICHEM. To obtain a High School-Science Teaching Efficacy Belief Instrument- biology (HS-STEBI-bio) variable, the word 'chemistry' was changed to 'biology' and the phrase 'section of science' was completely deleted. Also, "When student's grades in the chemistry section of science improve it is often due to their teacher having found a more effective teaching approach," is STEBI-CHEM item. To obtain HS-STEBI-bio variable, the word 'chemistry' was changed to 'biology' and the phrase 'section of science' was completely deleted. Also, "Even when I try very hard, I do not teach chemistry as well as I do most areas of science" is a variable in STEBICHEM. To obtain information for HS-STEBI-bio, the term 'chemistry' was replaced with 'biology,' and the phrase, 'most areas of science' was changed to 'other science subjects' (see Appendix A). 
Then, once the HS-STEBI-bio information was obtained, the HS-STEBI-phys was created by removing the word biology and replacing it with physics. The HS-STEBI-chem was obtained similarly. Each instrument is a 25 -item with five-point Likert scale, strongly agree, agree, neither, disagree, strongly disagree.

\section{5.5}

\section{Sample and Data Collection}

The participants were in-service biology, chemistry, and physics teachers who taught biology in the 2017-2018 school year in Texas public high schools. Qualtrics, an online survey platform, distributed simultaneously the three survey instruments HS-STEBI-phys, HS-STEBI-bio, and HS-STEBI-chem, to11,665 in-service physics, biology, and chemistry teachers. The Qualtrics 'skip logic' feature was used to exclude non-participants and to direct biology, chemistry, and physics respondents to an appropriate scale. A total of 562 participants responded to the biology instrument. Data from only biology respondents were analyzed in this study. Data were imported into the Statistical Package for the Social Sciences (SPSS) 25.0, and SPSS Analysis of a Moment Structures (AMOS) 25 for analysis.

Data Analysis and Results

Principal Component Analysis

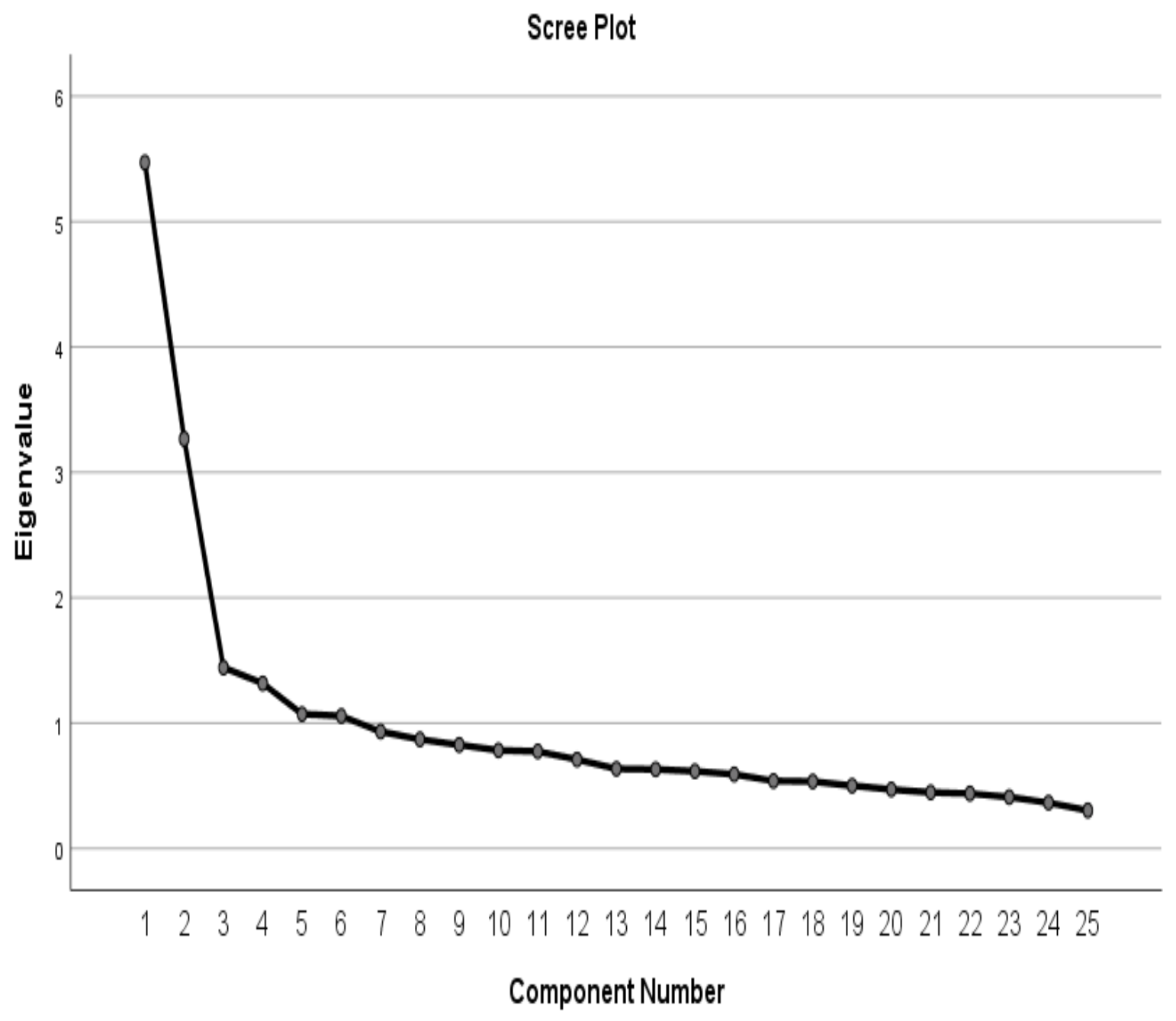

Figure 1. Scree plot of 25-item HS-STEBI-bio 


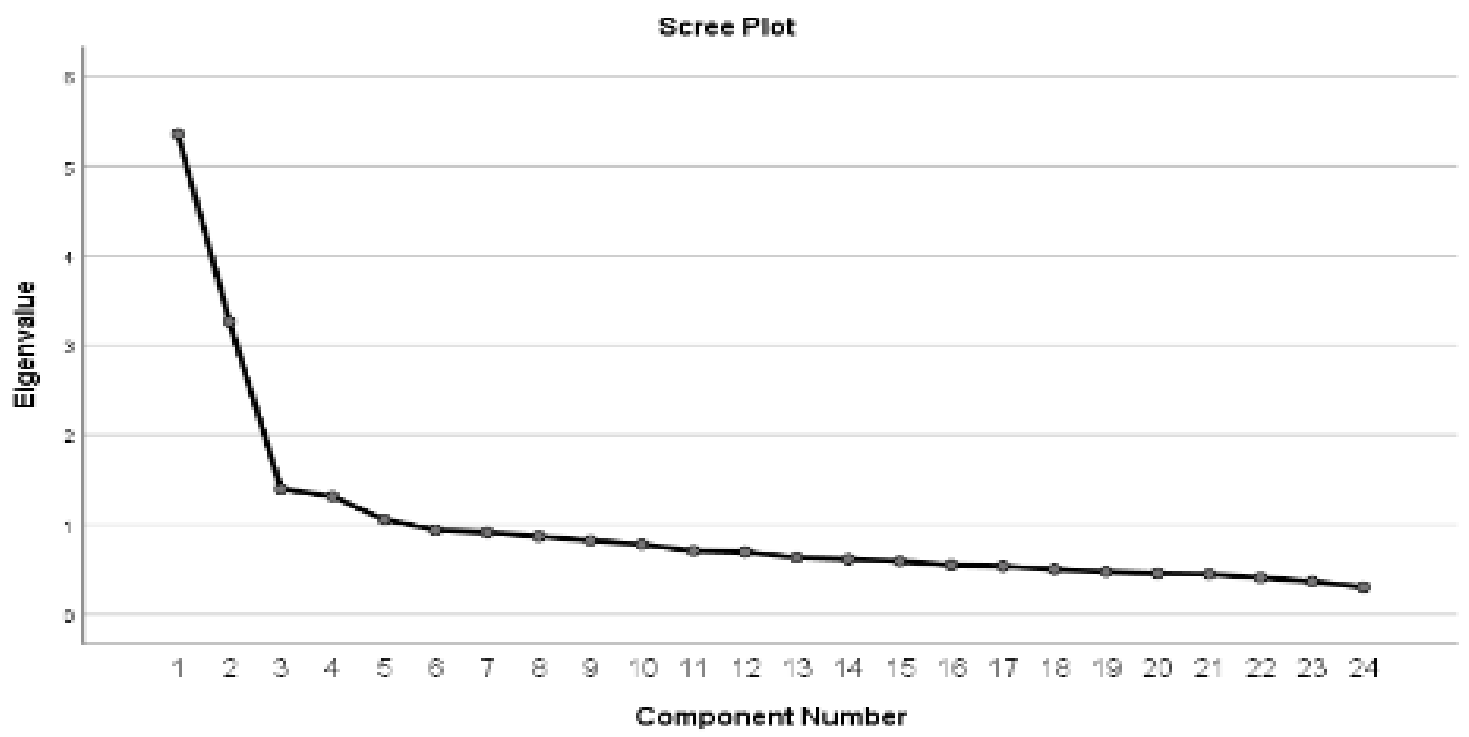

Figure 2. Scree plot of 24-item HS-STEBI-bio

Before conducting thePrincipal Component Analysis, negatively worded items (3, 10, 13, 19, 21, 22, 24, and 25) were reverse-coded. For example, item 25 (Even teachers with good teaching abilities cannot help some students learn biology.) is a negative item and scored in the survey as: $1=$ strongly agree, $2=$ agree, $3=$ neither, $4=$ disagree, and $5=$ strongly disagree but reverse-scored as $5=$ strongly agree, $4=$ agree, $3=$ neither, $2=$ disagree, and $\mathrm{I}=$ strongly disagree. Then, a Principal Component Analysis with varimax orthogonal rotation was conducted on the 25-item HSSTEBI-bio using SPSS statistics. The number of principal components to extract was fixed at two because of prior theory that efficacy has two subconstructs (Bandura, 1977, 1997; Riggs \& Enochs, 1990; Rubeck, 1990). The scree plot test showed two principal components could be retained (Figure 1). The first principal component was named "Personal Efficacy in Teaching Biology" while the second was labeled "Outcome Expectancy in Teaching Biology." The Personal Efficacy in Teaching Biology (PETB) resulted in an eigenvalue of 5.47 and explained 21.89 percent of the total variance. The Outcome Expectancy in Teaching Biology (OETB) recorded an eigenvalue of 3.27 and accounted for 13.07 percent of the total variance. Table 1 shows loadings on each principal component. A total of 13 items loaded into the PETB and 12 items described OETB. Each item recorded loadings .3, the lowest coefficient for retaining an item (Feld, 2013). However, item 13 cross-loaded highly to both principal components and, consequently, was removed. The PCA with varimax orthogonal rotation was repeated on 24 items. The Figure 2 shows the scree plot results with two distinct principal components. Again, 13 variables loaded into PETB while 11 variables defined OETB. All the loadings reached a coefficient of .3. as shown in Table 2. 
Table 1

First Trial Corrected Item - Total Scale Correlations and Component Loadings

\begin{tabular}{|c|c|c|c|c|c|}
\hline & & Positive- & Corrected & Comp & ent Loadings \\
\hline & Measure & Negative & $\begin{array}{l}\text { Item-Total } \\
\text { Correlation }\end{array}$ & 1 & 2 \\
\hline & Item 2 & $\mathrm{P}$ & 0.37 & 0.42 & 0.28 \\
\hline & Item 3 & $\mathrm{~N}$ & 0.47 & 0.57 & 0.03 \\
\hline Personal Efficacy & Item 5 & $\mathrm{P}$ & 0.59 & 0.70 & 0.15 \\
\hline in Teaching Biology & Item 6 & $\mathrm{P}$ & 0.49 & 0.56 & 0.15 \\
\hline & Item 8 & $\mathrm{P}$ & 0.62 & 0.75 & 0.13 \\
\hline & Item 12 & $\mathrm{P}$ & 0.51 & 0.65 & -0.00 \\
\hline & Item 17 & $\mathrm{P}$ & 0.40 & 0.46 & 0.23 \\
\hline & Item 18 & $\mathrm{P}$ & 0.45 & 0.57 & -0.05 \\
\hline & Item 19 & $\mathrm{~N}$ & 0.52 & 0.66 & -0.17 \\
\hline & Item 21 & $\mathrm{~N}$ & 0.32 & 0.38 & 0.05 \\
\hline & Item 22 & $\mathrm{~N}$ & 0.54 & 0.62 & 0.03 \\
\hline & Item 23 & $\mathrm{P}$ & 0.41 & 0.52 & 0.02 \\
\hline & Item 24 & $\mathrm{~N}$ & 0.51 & 0.57 & 0.22 \\
\hline Total Scale Alpha $=.81$ & & & & & \\
\hline & Item 1 & $\mathrm{P}$ & 0.47 & 0.06 & 0.61 \\
\hline & Item 4 & $\mathrm{P}$ & 0.55 & 0.13 & 0.67 \\
\hline & Item 7 & $\mathrm{P}$ & 0.48 & -0.12 & 0.62 \\
\hline & Item 9 & $\mathrm{P}$ & 0.47 & 0.14 & 0.57 \\
\hline & Item 10 & $\mathrm{~N}$ & 0.27 & -0.04 & 0.32 \\
\hline Outcome Expectancy & Item 11 & $\mathrm{P}$ & 0.52 & 0.11 & 0.65 \\
\hline & *Item 13 & $\mathrm{~N}$ & 0.27 & 0.25 & 0.30 \\
\hline & Item 14 & $\mathrm{P}$ & 0.47 & 0.03 & 0.59 \\
\hline & Item 15 & $\mathrm{P}$ & 0.58 & 0.04 & 0.68 \\
\hline & Item 16 & $\mathrm{P}$ & 0.42 & 0.18 & 0.53 \\
\hline & Item 20 & $\mathrm{P}$ & 0.56 & 0.19 & 0.65 \\
\hline & Item 25 & $\mathrm{~N}$ & 0.39 & 0.04 & 0.47 \\
\hline Total Scale Alpha $=.80$ & & & & & \\
\hline
\end{tabular}

* Item removed due to cross loading and low coefficient 
Table 2

Second Trial Corrected Item-Total Scale Correlations and Component Loadings

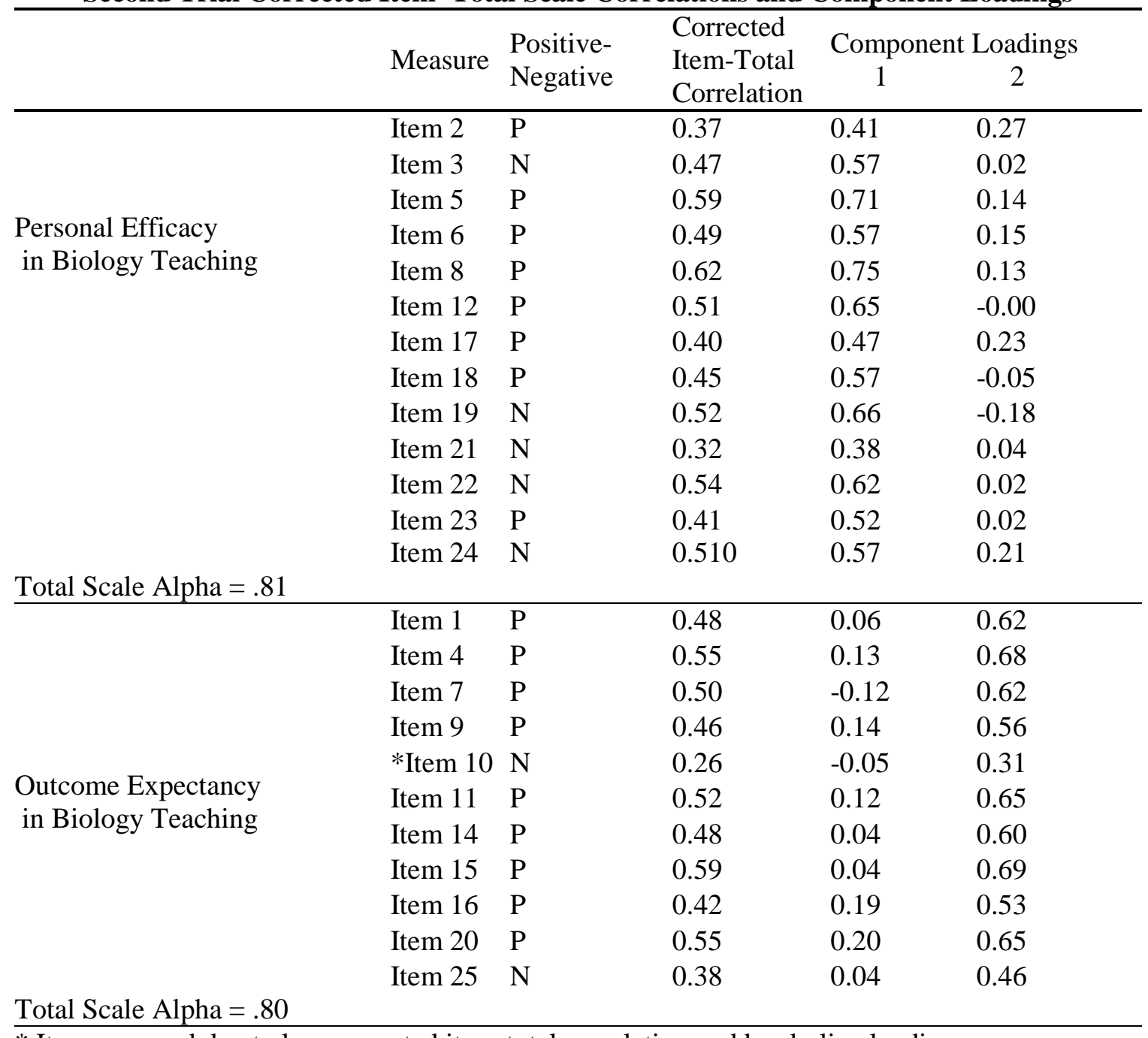

* Item removed due to low corrected item-total correlation and borderline loading 
Table 3

Final Corrected Item-Total Scale Correlations and Component Loadings

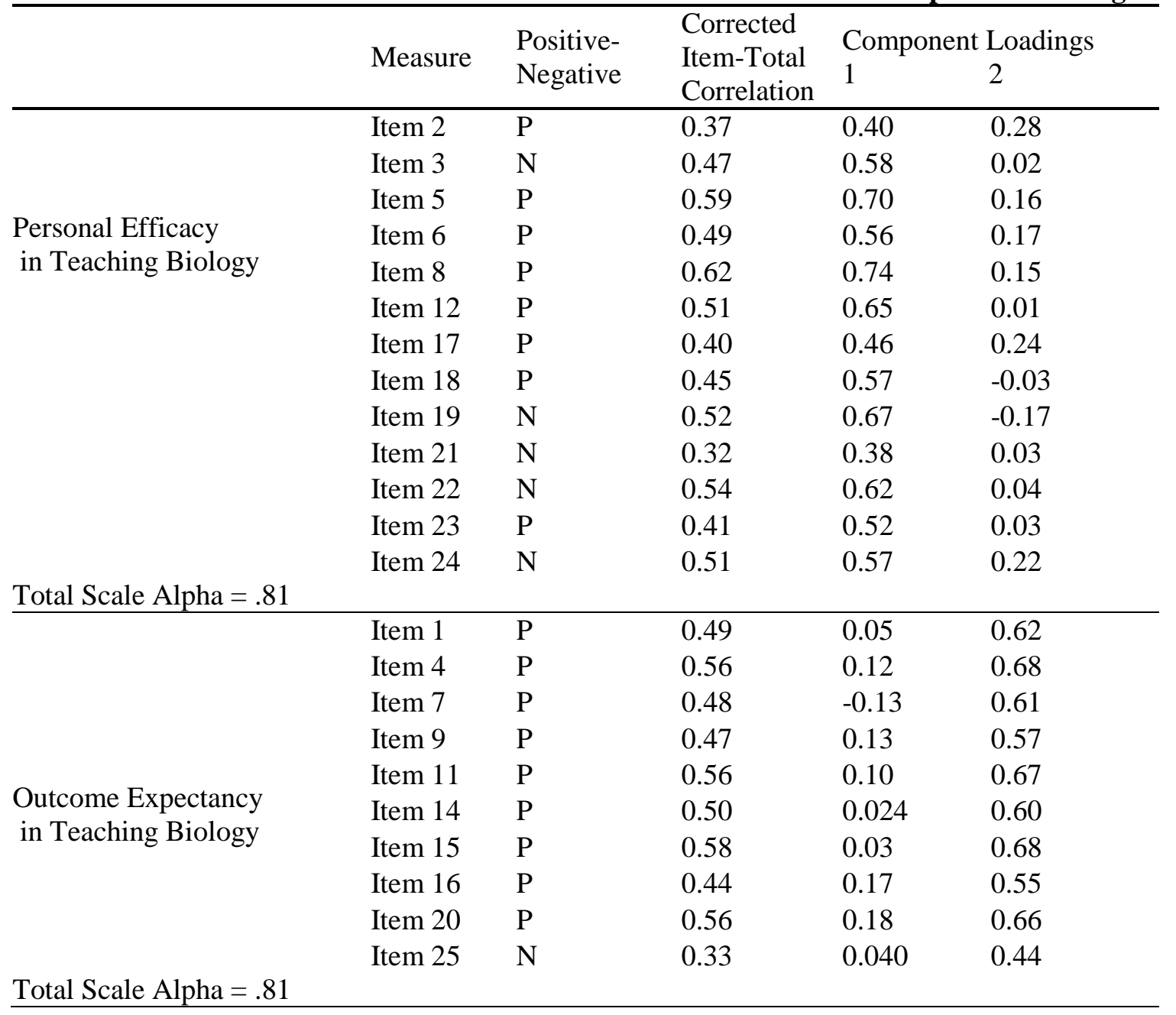

6.2

Reliability Test

The internal consistency reliability of both Personal Efficacy in Teaching Biology and Outcome Expectancy in Teaching Biology subscales was conducted using Cronbach's alpha. The results are reported in Table 2. The PETB subscale recorded overall alpha of .81, and the 13 items attained Corrected Item-Total Correlation of .3 and higher. The total reliability of OETB subscales was .80. Each variable in Table 2 reached a Corrected Item-Total Correlation of .3 except item 10 and was deleted from further analysis. 


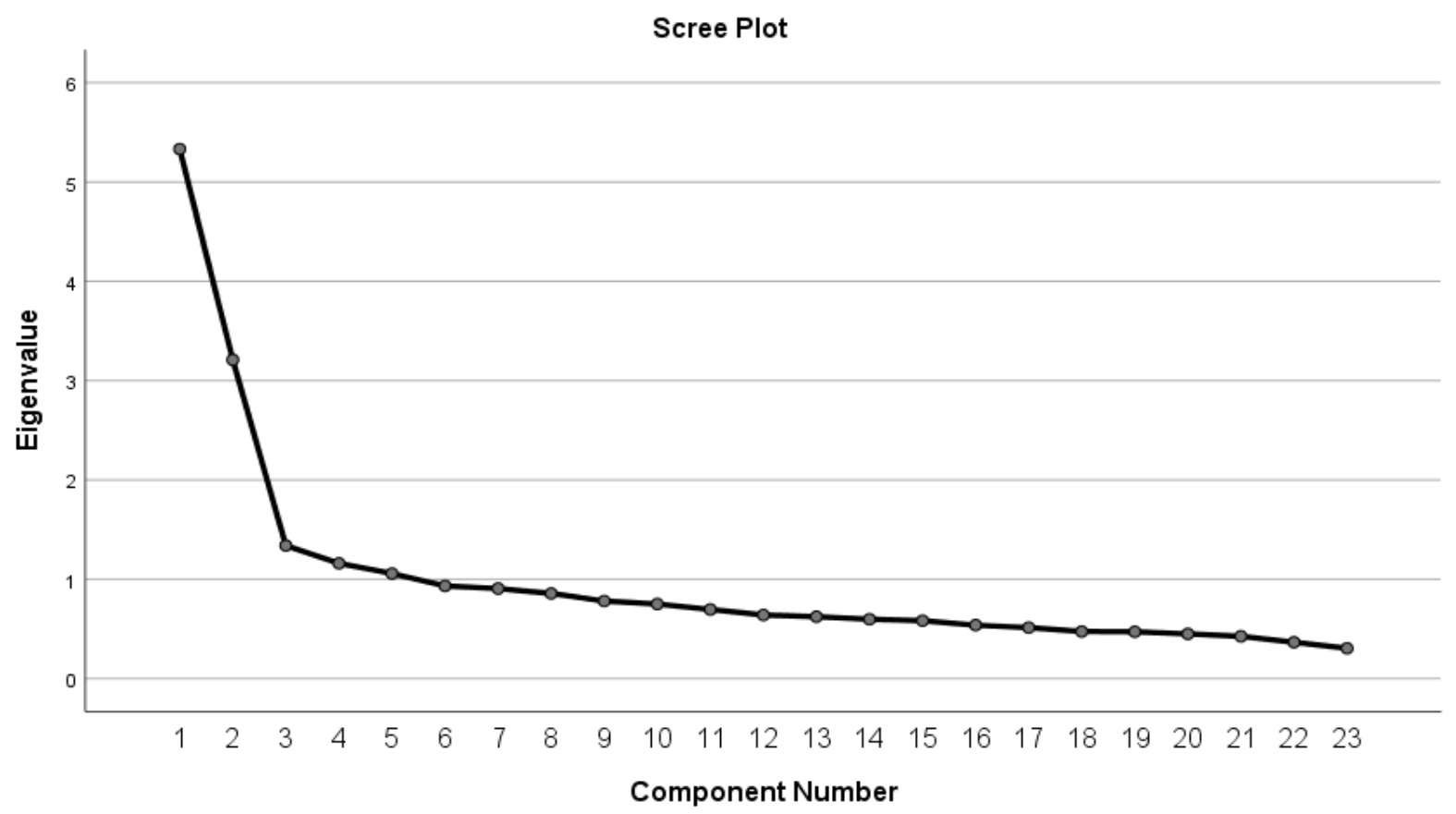

Figure 3. Scree plot of 23-item HS-STEBI-bio

Repeatedly, the PCA with varimax orthogonal rotation was conducted on the remaining 23 items. The scree plot results shown in Figure 3 continued to indicate two prominent principal components. Remarkably, the13 variables continued to load into the first principal components while the remaining 10 variables defined the second principal component. All the loadings were .3 and higher as shown in Table 3. Again, the internal consistency reliability of both PETB and OETB subscales was repeated using Cronbach's alpha. The PETB retained overall alpha of .81, and each item recorded Corrected Item-Total Correlation of .3 and higher. Clearly, the total reliability of OETB increased to .81, and the Corrected Item-Total Correlation of each variable went up to .3 and above. The reliability test results are reported in Table 3. The Table 3 shows the final results of PCA and reliability test results.

\section{Confirmatory Factor Analysis}

A Confirmatory Factor Analysis is an ideal test for assessing the validity of an existing instrument such as STEBI or STEBI-CHEM. Thus, a Confirmatory Factor Analysis (CFA) was conducted to support the validity of HSSTEBI-bio as an instrument with two principal components. Using SPSS AMOS, a CFA was performed on the 25item HS-STEBI-bio (13 PETB and 12 OETB). The model fit was determined with four indexes, Root Mean Square Error of Approximation (RMSEA), Comparative Fit Index (CFI), Normal Fit Index (NFI), and Goodness of Fit Index (GF1). All of the estimated coefficients reached statistical significance, $p<.001$, however, items 10 , 13, and 21 failed to reach .3 coefficient and were removed. The CFA was repeated. All the weights reached .3, but the indexes could not attain acceptable baseline for a good model fit, RMSEA $=.08, \mathrm{CFI}=.82, \mathrm{NFI}=.77$, and $\mathrm{GFI}=.87$. The analysis was discontinued since the purpose of the study was not exploratory.

\section{Significance of Study}

The results of PCA, CFA, and reliability tests highlighted the importance of studying validity and reliability of STEBI before use in a high school context with biology teachers. Deletion of items 10 and 13 from the scale reduced HS-STEBI-bio to a 23-item scale (see Appendix B). Thus, HS-STEBI-bio differs slightly from the existing STEBI and STEBI-CHEM which were each defined by 25 variables. However, the personal efficacy variables were consistent with the results obtained by predecessors (Riggs \& Enochs, 1990; Rubeck, 1990). The difference lies with the outcome expectancy variables. The biology teachers did not consider the negative items, "The low science achievement of some students in biology cannot be blamed on their teachers", and, "increased effort in teaching biology produces little change in students' biology achievement", as measures of their belief that effective teaching will improve students' learning. 
Further, the CFA results showed that the data failed to fit the model. Consequently, the PCA only supported the validity of the HS-STEBI-bio. Nonetheless, the PCA and reliability test results seemed to indicate that HS-STEBIbio is a valid and reliable instrument to measure teaching efficacy beliefs of biology teachers in high school settings. Overall, the validity and reliability test results showed that STEBI-CHEM could be modified and the resulting HS-STEBI-bi ocould be used to study teaching efficacy beliefs of biology teachers.

\section{References}

Angle, J., \& Moseley, C. (2009). Science teacher efficacy and outcome expectancy as predictors of students' end- of- instruction (EOI) biology I test scores. School Science and Mathematics, 109(8), 473-483.

Ashton, P. T., \& Webb, R. B. (1986). Making a difference: Teachers' sense of efficacy and student achievement. NY, Longman Publishing Group.

Bandura, A. (1989). Human agency in social cognitive theory. American psychologist, 44(9), 1175

Bandura, A., \& Cervone, D. (1986). Differential engagement of self-reactive influences in cognitive motivation. Organizational Behavior and Human Decision Processes, 38(1), 92-113.

Bandura, A. (1977). Self-efficacy: Toward a unifying theory of behavioral change.Psychological Review, 84(2), 191.

Cakiroglu, J., Capa-Aydin, Y., \& Hoy, A. W. (2012). Science teaching efficacy beliefs. In Second International Handbook of Science Education(pp. 449-461). Springer, Dordrecht.

Czerniak, C. L. (1989). An investigation of the relationships among science teaching anxiety, self-efficacy, teacher education variables, and instructional strategies. (Doctoral dissertation, The Ohio State University).

Czerniak, C. M., \& Schriver, M. L. (1994). An examination of preservice science teachers' beliefs and behaviors as related to self-efficacy. Journal of Science Teacher Education, 5(3), 77-86.

Hoy, W. K., \& Woolfolk, A. E. (1990). Socialization of student teachers.American Educational Research Journal,27(2), 279-300.

Enochs, L. G., Smith, P. L., \& Huinker, D. (2000). Establishing factorial validity of the mathematics teaching efficacy beliefs instrument. School Science and Mathematics, 100(4), 194-202.

Field, A. (2013). Discovering statistics using IBM SPSS statistics. Sage.

Lumpe, A., Czerniak, C., Haney, J., \& Beltyukova, S. (2012). Beliefs about teaching science: The relationship between elementary teachers' participation in professional development and student achievement. International Journal of Science Education, 34(2), 153-166.

Riggs, I. M., \& Enochs, L. G. (1990). Toward the development of an elementary teacher's science teaching efficacy belief instrument. Science Education, 74(6), 625-637.

Rubeck, M. L. H. (1990). Path analytical models of variables that influence science and chemistry teaching selfefficacy and outcome expectancy in middle school science teachers (Doctoral dissertation, Kansas State University, Kansas).

Wenner, G. (2001). Science and mathematics efficacy beliefs held by practicing and prospective teachers: A 5-year perspective. Journal of Science Education and Technology, 10(2), 181-187. 


\title{
Appendix
}

\section{Appendix A}

\section{Adaptation of High School-Science Teaching Efficacy Belief Instrument-Biology}

\author{
Adaptation of High School-Science Teaching Efficacy Belief Instrument-Biology \\ Original STEBI-CHEM \\ Adapted HS-STEBI-bio \\ 1.When a student does better in the chemistry \\ section of science it is often because the \\ teacher exerted a little extra effort. \\ 1. When a student does better than usual in \\ biology, it is often because the teacher exerted \\ a little extra effort. \\ 2.I am continually finding better ways to \\ teach chemistry. \\ 2. I continuously find better ways to teach \\ biology. \\ 3.Even when I try very hard, I do not teach \\ chemistry as well as I do most areas of \\ 3. Even if I try very hard, I do not teach \\ biology as well as I teach other sciences.
} science.

4. When students grades in the chemistry section of science improve it is often due to their teacher having found a more effective teaching approach.

5.I know the steps necessary to teach chemistry concepts effectively.

4. When the biology grades of students improve, it is often due to their teacher having found a more effective teaching approach.

5. I am able to teach biology concepts effectively. 6. I am effective in monitoring hands-on biology activities.

chemistry experiments.

7.If students are underachieving in the chemistry section of science it is most likely due to ineffective chemistry teaching. 8. I generally teach the chemistry section of scienceineffectively.

9.The inadequacy of a student's background in chemistry can be overcome by good teaching.

10.The low science achievement of some students in the chemistry section of science cannot be blamed on their teachers.

11. When a low-achieving child progresses in the chemistry section of science it is usually due to extra attention given by the teacher. 12.I understand chemistry concepts well enough to be effective in teaching middle school chemistry. 13.Increased effort in chemistry teaching produces little change in some students' chemistry achievement.

14.The teacher is generally responsible for the achievement of students in the chemistry section of science.

15.Students' achievement in the chemistry section of science is directly related to their teachers' effectiveness in teaching. 16.If parents comment that their child is showing more interest in the chemistry section of science at school, it is probably due

7. If students are underachieving in biology, it is most likely due to ineffective teaching.

8.Igenerally teach biology concepts ineffectively.

9. The inadequacy of a student's background in the science of biology can be overcome by good teaching.

10. The low science achievement of some students in biology cannot be blamed on their teachers.

11. When a low-achieving student progresses in biology, it is usually due to extra attention given by the teacher.

12. I understand biology concepts well enough to be an effective high school biology teacher.

13. Increased effort in teaching biology produces little change in students' biology achievement.

14. The teacher is generally responsible for the achievement of students in biology.

15. Students' achievement in biology is directly related to their teachers' effectiveness.

16. If parents comment that their child is showing more interest in biology at school, it is probably due to performance of the child's 
to performance of the child's teacher. 17.I find it difficult to explain to students why chemistry experiments work.

18.I am typically able to answer students' chemistry questions.

19.I wonder if I have the necessary skills to teach the chemistry section of science.

20.Effectiveness in chemistry teaching has little influence on the achievement of students with low motivation.

21. Given the choice I would not invite the principal to evaluate my science teaching in chemistry.

22. When a student has difficulty understanding a chemistry concept I am usually at a loss as to how to help the student understand it better.

23. When teaching chemistry, I usually welcome students' questions.

24.I do not know what to do to turn students on to chemistry.

25.Even teachers with good teaching abilities cannot help some kids to learn chemistry. teacher.

17. I find it easy to use hands-on activities such as experiments and demonstrations to explain biology concepts to students.

18. 1 am able to answer students' biology questions.

19. I wonder if I have the necessary skills to teach biology.

20. Effective biology teachers influence lowmotivated students' achievement.

21. Given a choice, I would not invite my principal to evaluate my biology teaching.

22. When a student has difficulty understanding a biology concept, I am usually at a loss as to how to help the student understand it better.

23. When teaching biology, I usually welcome students' questions.

24. I do not know what to do to turn students on to biology.

25. Even teachers with good teaching abilities cannot help some students to learn biology.

\section{Appendix B \\ High School - Science Teaching Efficacy Belief Instrument-Bio}

\section{High School - Science Teaching Efficacy Belief Instrument-Bio}

Please indicate the degree to which you agree or disagree with each statement below by checking appropriate box to the right of each statement.

SA = STRONGLY AGREE

$\mathrm{A}=$ AGREE

$\mathrm{UN}=\mathrm{UNCERTAIN}$

$\mathrm{D}=$ DISAGREE

$\mathrm{SD}=\mathrm{STRONGLY}$ DISAGREE

Note: Item 10 and item 13 were deleted

1.When a student does better than usual in biology,

SA A N D SD

it is often because the teacher exerted a little extra effort.

2. I continuously find better ways to teach biology.

SA A N D SD

3. Even if I try very hard, I do not teach biology as

SA A N D SD

well as I teach other science subjects.

4. When the biology grades of students improve,

SA A N D SD

it is often due to their teacher having found a more

effective teaching approach.

5. I am able to teach biology concepts effectively.

SA A N D SD

6. I am effective in monitoring hands-on biology activities.

SA A N D SD

7. If students are underachieving in biology, it is most

SA A N D SD

likely due to ineffective teaching.

8. I generally teach biology concepts ineffectively.

SA A N D SD

9. The inadequacy of a student's background in

SA A N D SD

the science of biology can be overcome by good teaching. 
*10. The low science achievement of some students

in biology cannot be blamed on their teachers.

11. When a low-achieving student progresses in biology,

SA A N D SD

it is usually due to extra attention given by the teacher.

12. I understand biology concepts well enough to be an effective high school biology teacher.

* 13 . Increased effort in teaching biology produces

little change in students' biology achievement.

14. The teacher is generally responsible for the

SA A N D SD

achievement of students in biology.

15. Students' achievement in biology is directly

SA A N D SD

related to their teachers' effectiveness.

16. If parents comment that their child is showing more

SA A N D SD

interest in biology at school, it is probably due to the

performance of the child's teacher.

17. I find it easy to use hands-on activities such as

SA A N D SD

experiments and demonstrations to explain biology

concepts to students.

18. I am able to answer students' biology questions.

SA A N D SD

19. I wonder if I have the necessary skills to teach biology.

SA A N D SD

20. Effective biology teachers influence low-motivated

SA A N D SD

students' achievement.

21. Given a choice, I would not invite my principal to

SA A N D SD

evaluate my biology teaching.

22. When a student has difficulty understanding a biology

SA A N D SD

concept, I am usually at a loss as to how to help the

student understand it better.

23. When teaching biology, I usually welcome students' questions.

SA A N D SD

24. I do not know what to do to turn students on to biology.

SA A N D SD

25 . Even teachers with good teaching abilities cannot

SA A N D SD

help some students to learn biology.

Note: *Item deleted from HS-STEBI-bio 